\title{
Appearance comparisons and body image in women's everyday lives
}

\author{
Jasmine Fardouly, Lenny Vartanian \\ From 2015 ANZAED Conference: Riding the Waves to Recovery \\ Surfers Paradise, Australia. 21-22 August 2015
}

\begin{abstract}
Appearance comparisons are an important socio-cultural factor influencing body dissatisfaction among young women. These appearance comparisons can occur when interacting with another person, reading magazines, watching television, or when engaging with social media. However, little is known about the frequency and outcome of appearance comparisons through these different mediums in women's everyday lives. We conducted an Ecological Momentary Assessment study in which female undergraduate students $(n=150)$ completed a brief online survey at five random times every day for five days. In this survey, participants were asked if they had made an appearance comparison. If they had, they were also asked what medium they compared themselves through and how they rated compared to that person (i.e., more attractive, less attractive). All participants then completed state measures of mood, appearance dissatisfaction, and intention to diet and exercise. Participants reported comparing themselves most often to others in person, and in person comparisons were associated with less negative outcomes (e.g., less body dissatisfaction) than were comparisons through other mediums (e.g., social media). These findings suggest that appearance comparisons are not always bad, but it is specifically comparisons to idealised images (whether through traditional or social media) that is associated with negative outcomes.
\end{abstract}

Published: 23 November 2015

doi:10.1186/2050-2974-3-S1-020

Cite this article as: Fardouly and Vartanian: Appearance comparisons and body image in women's everyday lives. Journal of Eating Disorders 2015 3(Suppl 1):O20.

* Correspondence: jasmine.fardouly@unsw.edu.au UNSW Australia, Australia

(0) 2015 Fardouly and Vartanian This is an Open Access article distributed under the terms of the Creative Commons Attribution License (http://creativecommons.org/licenses/by/4.0), which permits unrestricted use, distribution, and reproduction in any medium, provided the original work is properly cited. The Creative Commons Public Domain Dedication waiver (http://creativecommons.org/ publicdomain/zero/1.0/) applies to the data made available in this article, unless otherwise stated. 